\title{
Effect of activated carbon in PSF-PEI-Ag symmetric membrane
}

\author{
Khairul Anwar Mohamad Said ${ }^{1}$, Genevieve Gadung George ${ }^{1}$, Nurul Ain Mohamed Alipah ${ }^{1}$, Nor Zakirah Ismail ${ }^{1}$, Ramizah \\ Liyana Jama'in ${ }^{1}$ \\ ${ }^{1}$ Department of Chemical Engineering and Energy Sustainability, UNIMAS, 94300, Kota Samarahan, Sarawak, Malaysia
}

\begin{abstract}
Polysulfone (Psf) composite membrane consist of activated carbon, polyethyleneimine and silver nitrate was prepared by phase inversion. The activated carbon (AC) act as adsorbent to adsorb heavy metal present in synthetic waste water while polysulfone membrane act as support. Phase inversion was carried out on different composition of activated carbon from 0 to $0.9 \%$ while other component are remain constant. The surface morphology of composite membrane was characterized by scanning electron microscopy (SEM) while heavy metal absorption was quantified by atomic absorption spectrometer (AAS). The SEM image show symmetric membrane matrix with sponge structure. The composite membrane with $0.9 \mathrm{wt} \% \mathrm{AC}$ has the highest water flux as well as removal of heavy metal (chromium, lead, silver and cadmium) compare to composite membrane with $0.3 \mathrm{wt} \% \mathrm{AC}$ and $0.5 \mathrm{wt} \% \mathrm{AC}$. The percentage of heavy metal reduction by composite membrane $0.9 \mathrm{wt} \% \mathrm{AC}$ was $35 \%$ cadmium, $19 \%$ chromium, $16 \%$ silver and $2 \%$ lead. The result indicated that the introduction of $0.9 \mathrm{wt} \% \mathrm{AC}$ indeed plays an important role towards enhancing the adsorption of heavy metal in water
\end{abstract}

\section{Introduction}

Membrane comes in different meanings where it is defined as an intervening phase separating two phases acting as a barrier to transport matter between phases. Membrane separates substances through its pore using momentum such as pressure difference, temperature difference, concentration and electric potential difference [1].

Membranes have gained an important place in chemical technology and have been utilized on broad range of applications. Among the application including manufacturing, medical, water treatment and fuel cells [2]. For example, in wastewater treatment, membrane successfully treat wastewater up to $98 \%$ rejection of heavy metals [3].

Malaysia get 2,000 to $3,000 \mathrm{~mm}$ rainfall a year, recorded as the seventh highest in the world. But, most of it is lost to surface run-off, evaporation and groundwater recharge that is often used for drinking water. In Malaysia, water resources can be obtained from rainfall, surface runoff, groundwater recharge, dams, aquifers and evapotranspiration. On top of that, streams and river also contribute $98 \%$ of total water used in Malaysia.

Problem arises when heavy metals from industrial and consumer enter water into the streams, lakes, rivers and groundwater. In the end, water are polluted with heavy metal residue and possess danger to aquatic organism. Heavy metals are categorized as metallic elements having atomic weights between 63.5 and 200.6, and a specific gravity greater than 5.0. Unlike other organic contaminants, heavy metals are not biodegradable.
A major concern involved heavy metal with carcinogenic effect such as chromium, cadmium, lead, zinc, and copper [4]. In addition, these heavy metal are usually found in industrial wastewater and at large amount of discharge would lead to significant effect to aquatic life either acute or chronic toxicity [5]. Therefore, it is vital to treat and process the effluent before discharge

There are several proposed methods available for treatment of heavy metal in wastewater including microbial system, electrochemical process, chemical precipitation, coagulation, adsorption, membrane filtration and etc [6]. All the proposed treatment are divided into three categories mainly chemical, physical and biological treatment where the latter are widely known for its low economic implication and environmental friendly [7]. Despite the advantages, biological treatment would require large land area to fully utilize its performance which brings physical treatment in main picture as the substitute.

Membrane technology is one of the promising physical treatments that would solve the wastewater problem. Apart from membrane, activated carbon are being widely used by various researchers for the removal of heavy metal. Activated carbon is a carbonaceous material with a highly developed porous structure and large surface functional group which makes it capable of distributing toxic elements on its surface $[8,9]$.

The adsorption process usually associated with activated carbon happened when molecule of gases or liquids (adsorbent) attached to the surface of activated carbon (adsorbate). In theory, there are three step associated with adsorption process start with macro 
transport which refer to movement of particle with size of more than $50 \mathrm{~nm}$ followed by micro transport for particles size of less than $2 \mathrm{~nm}$ and finally sorption process. Sorption involved a physical attachment of organic material onto adsorbate surface. Example of industrial application utilizing adsorption process were water purification by using synthetic resin and activated charcoal as adsorbate [10].

Hence, activated carbon has been known widely as a good adsorbate and the idea of incorporating activated carbon into membrane matrix has not been fully explored. The properties of activated carbon as a highly amorphous solid with micro crystallite and graphic lattice would increase adsorption performance especially in this context the heavy metal present in wastewater [10]. Therefore, this study proposed a composite membrane consist of polysulfone, polyethyleneimine, n-methyl-2pyrrolidone, silver nitrate and activated carbon to reduce heavy metals present in the wastewater.

\section{Methodology}

\subsection{Materials and Chemicals}

Polysulfone (PSf, MW 35,000 gmol-1), Polyethyleneimine (PEI, MW 25,000 gmol-1) in powder form, and N-Methyl-2-pyrrolidone (NMP, 99.5\%) are obtained from Sigma-Aldrich. Silver nitrate (AgNO3, MW 169.87 gmol-1) and granular activated carbon (AC) synthesized from palm kernel shell.

\subsection{Preparation of Composite Membrane}

Silver nitrate, polyethyleneimine and activated carbon are slowly added in PSf/NMP solution and continued stirred until completely dissolved. These solutions were further agitated for another 24 hours to reach homogeneous mixing. Then, the membrane solutions were cast on a clean, dry, level glass plate. Casting was carried out at ambient atmosphere, $30^{\circ} \mathrm{C} .5$ $\mathrm{ml}$ of casting solution was poured onto a glass plate for gap setting of $100 \mu \mathrm{m}$ and left for evaporation process. After 1 minute evaporating time, membranes were immersed in deionized water for 1 hour at room temperature to allow membrane formation. Membrane were washed in deionized water to remove remaining solvent and finally leaved to dry at room temperature for 1 day. There were five membranes to be fabricated. Table 1 shows the membrane composition of all composite membrane (CM).

Table 1. Composite membrane composition

\begin{tabular}{|l|l|c|c|c|c|}
\hline Type & $\begin{array}{c}\text { Psf } \\
\text { (wt. \%) }\end{array}$ & $\begin{array}{c}\text { NMP } \\
\text { (wt. \%) }\end{array}$ & $\begin{array}{c}\text { PEI } \\
\text { (wt. \%) }\end{array}$ & $\begin{array}{c}\text { AgNO } \\
\text { (wt. \%) }\end{array}$ & $\begin{array}{c}\text { AC } \\
\text { (wt. \%) }\end{array}$ \\
\hline CM 1 & 15.0 & 85.0 & - & - & - \\
\hline CM 2 & 15.0 & 84.2 & 0.3 & 0.5 & 0.0 \\
\hline CM 3 & 15.0 & 83.9 & 0.3 & 0.5 & 0.3 \\
\hline CM 4 & 15.0 & 83.7 & 0.3 & 0.5 & 0.5 \\
\hline CM 5 & 15.0 & 83.3 & 0.3 & 0.5 & 0.9 \\
\hline
\end{tabular}

\subsection{Membrane Characterization}

Morphologies of composite membranes with different weight of activated carbon were observed by scanning electron microscopy (SEM, JEOL JSM6390LA). SEM was used to analyse the surface and cross section of the membrane. It was operated at magnification of $100,000 \mathrm{x}$ and membrane were coated with gold sputter under vacuum condition prior to SEM. For analysing the cross-section, membrane was prepared in liquid nitrogen and placed vertically onto SEM stubs covered with carbon tape. Meanwhile for a surface analysis, membranes were placed horizontally on SEM stubs covered with carbon tape.

For water flux test, each flat sheet membrane was cut into circular form and immersed in deionized water for 5 minutes prior to dead-end filtration test. Filtration test was conducted by pouring $30 \mathrm{ml}$ of water into cell with membrane at the end as filter under pressure of 2 bar while running for 10 minutes.

The flow of filtered water was directly perpendicular to the membrane surface. Equation 1 shows the formula of flux, JW, is

$$
J_{w}=\frac{V}{A \Delta t}
$$

where $\mathrm{V}$ is volume of permeated water $(\mathrm{L}), \mathrm{A}$ is the effective area of membrane $\left(\mathrm{m}^{2}\right)$ and $\Delta \mathrm{t}$ is the time taken (hour) of permeated to filter.

\subsection{Adsorption Test}

Four different wastewater were prepared for adsorption test; chromium $(\mathrm{Cr})$, lead $(\mathrm{Pb})$, silver $(\mathrm{Ag})$ and cadmium $(\mathrm{Cd})$. The synthetic wastewater containing $\mathrm{Cr}$, $\mathrm{Pb}$ and $\mathrm{Cd}$ was prepared by dissolving $0.05 \mathrm{~g}$ of $\mathrm{K}_{2} \mathrm{Cr}_{2} \mathrm{O}_{7}$, $\mathrm{Pb}\left(\mathrm{NO}_{3}\right)_{2}, \mathrm{Ag}\left(\mathrm{NO}_{3}\right)$ and $\mathrm{Cd}\left(\mathrm{NO}_{3}\right)_{2} \cdot 4 \mathrm{H}_{2} \mathrm{O}$ in $500 \mathrm{ml}$ deionized water. The initial concentration of elements in synthetic wastewater solution was determined by Atomic Absorption Spectrometer (AAS). Prepared synthetic waste water was stored in tight bottle to prevent changes of concentration through evaporation/condensation.

Heavy metal adsorption test was conducted with dead end filtration system where $50 \mathrm{ml}$ of synthetic wastewater solution was poured into the cell. The composite membranes were cut into circular with a diameter of 44.5 $\mathrm{mm}$. The test was conducted under pressure of 3 bar for a duration of 30 minutes. Final concentration of permeated solution was determined by AAS.

AAS is used to measure the concentration of chemical elements usually for environmental related samples. The removal efficiency is obtained from equation 2:

$$
R(\%)=\frac{C_{0}-C_{t}}{C_{0}} \times 100
$$

where $\mathrm{C}_{0}$ and $\mathrm{C}_{\mathrm{t}}$ are the initial and final concentrations of heavy metals present in the wastewater before and after adsorption. 
The silver leached out from the membranes was also investigated by using AAS. Membranes were cut into 1 $\mathrm{cm} \times 1 \mathrm{~cm}$ area and subsequently immersed in $10 \mathrm{ml}$ of sodium chloride solution. After 1 to 2 days of being in contact with sodium chloride solution, the membranes were removed and the aqueous solutions analyzed.

\section{Result and Discussion}

\subsection{Membrane Morphology}

According to the literature, membrane structure has two forms either a symmetric or an asymmetric structure. Symmetric membrane is a membrane with a uniform structure while asymmetric membrane has a gradient structure[1]. Besides that, symmetric membrane have cylindrical, sponge and dense film structure. For asymmetric, it can be categorized into integralasymmetric and thin film composite[11].

Figure 1 presented the surface and cross-section of SEM images of membranes with different composition. CM1 was a membrane with PSf/NMP only. CM 2, CM 3, CM 4 and CM 5 were a composite membrane with $0 \%, 0.3 \%$, $0.5 \%$ and $0.9 \%$ weight fraction of activated carbon, respectively.

The cross section areas of membranes induced by phase inversion showed a symmetric structure with a lot of micro void appear across membrane matrix. According to Pinnau and Freeman (2000), cross-section of a typical polysulfone membrane prepared with phase inversion are usually has symmetric structure along with formation of micro void within matrix. On top of that, increased AC content to $0.9 \mathrm{wt}$ \% (CM5) were a clear evident for formation of sponge structure as shown Figure 1 (i) and (j). which aligned with stipulation stated the increase amount of activated carbon, cause pore to broaden/enlarge, thus increasing membrane structure porosity [12].

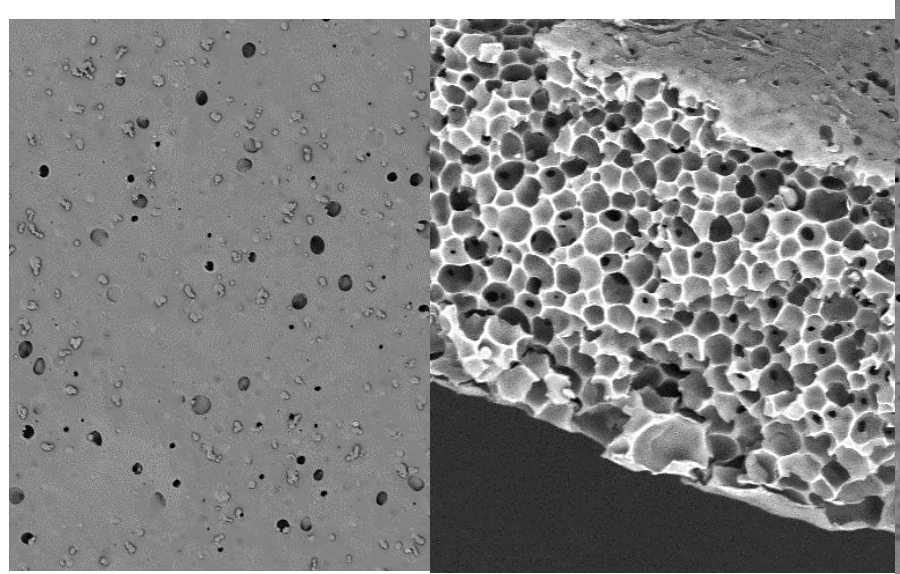

(a)

(b)

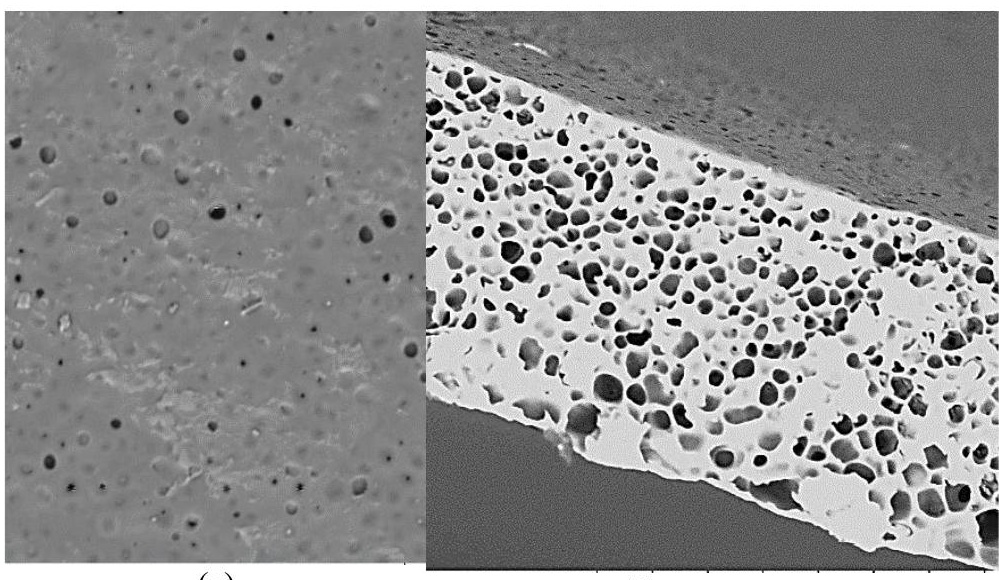

(c)

(d)

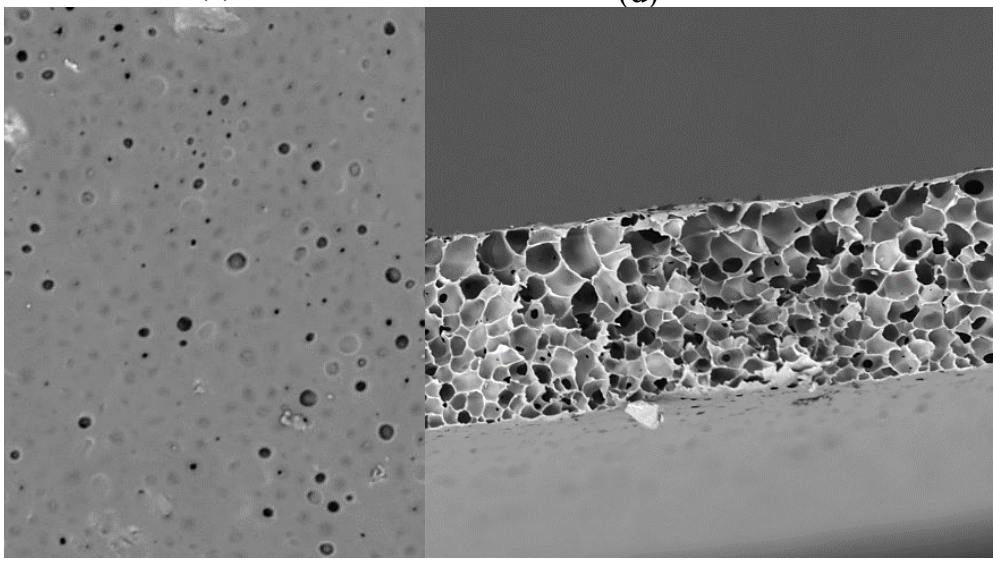

(e)

(f)

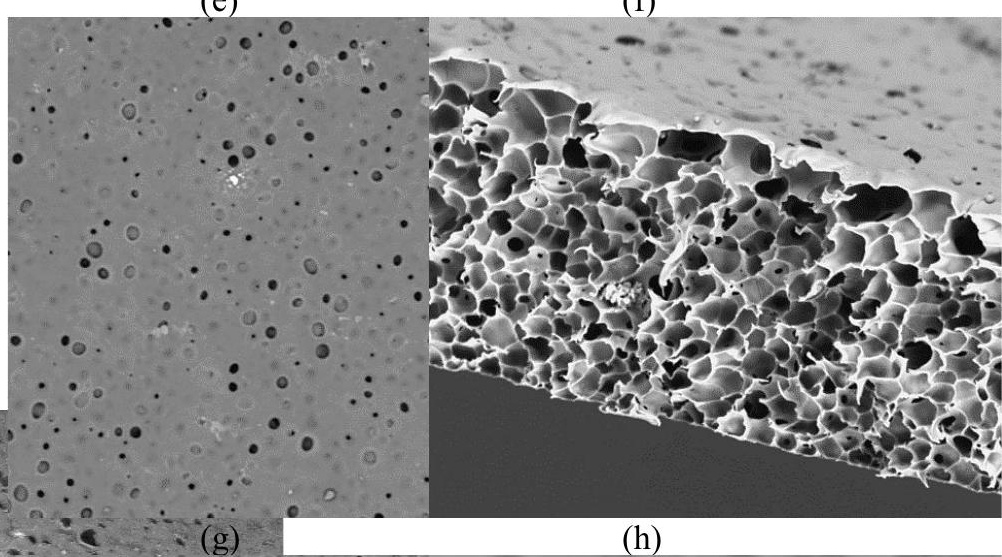

(g) $\quad(\mathrm{h})$

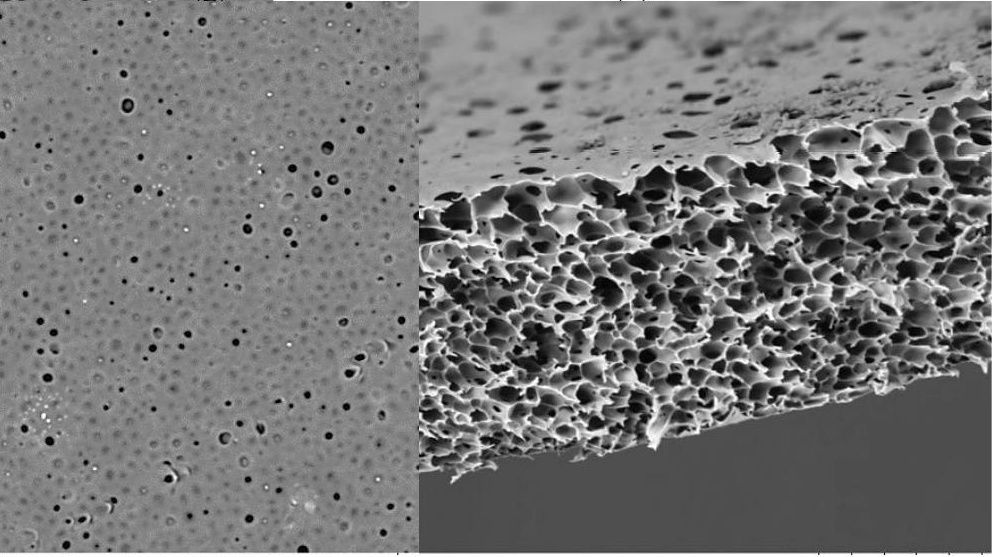

(i)

(j)

Figure 1. SEM images of top surface and cross section of composite membrane CM1(a,b), CM2(c,d), CM3(e,f), $\mathrm{CM} 4(\mathrm{~g}, \mathrm{~h})$ and $\mathrm{CM} 5(\mathrm{i}, \mathrm{j})$ 
Therefore, by adding different composition of activated carbon will result with increased in surface areas, pore volume, and sizes of pores. Comparing the surface and cross sectional morphologies of CM 1 to $\mathrm{CM}$ 5 , it was clearly shows that the membrane structures were changed as AC content increased.

\subsection{Water flux test}

Water flux and rejection are two most important parameters for membrane applications [13]. The water flux testing provided an indication of the membrane hydraulic performance. To recap, membrane were subjected to filtration test at pressure of 2 bar for 10 minute continuously. The result for water flux is as shown in Table 2.

Table 2. Water flux of various composite membrane

\begin{tabular}{|c|c|c|}
\hline Membrane & $\begin{array}{c}\text { Activated } \\
\text { carbon (wt\%) }\end{array}$ & Water flux (L/m² $\cdot \mathrm{hr})$ \\
\hline CM1 (Control) & - & 5.54 \\
\hline CM2 & 0 & 9.94 \\
\hline CM3 & 0.3 & 11.15 \\
\hline CM4 & 0.5 & 22.25 \\
\hline CM5 & 0.9 & 49.33 \\
\hline
\end{tabular}

The water flux increased when the AC was incorporated into the membranes. This result is attributed to the increase of membrane hydrophilicity and possibly by the increase in porosity [14]. Hydrophilicity refer to the affinity of the membrane material for water or ability of the membrane to become wetted with water [15].

CM 1 shows the lowest water flux than CM 5 with a difference of $43.79 \mathrm{~L} / \mathrm{m} 2 \mathrm{hr}$ which is a significant increase of $88 \%$ water flux performance. Based on Figure 1 , the large difference of water flux was expected because CM1 has a dense structure with a distinct honeycomb pattern unlike CM5 with porous-like structure. Also, the addition of silver nitrate has contribute to increase in water flux for CM2 from $5.54 \mathrm{~L} / \mathrm{m} 2$.hr (CM1) to 9.94 $\mathrm{L} / \mathrm{m} 2$.hr (CM2).

Andrade et al. (2015) studied water flux performance of polysulfone membranes modified with silver nanoparticles prepared by phase inversion method. In the event of silver nitrate addition, a significant increase of water flux was observed with increase composition of silver in membrane.

On the other hand, studies developed by Hwang et al. (2013), water flux of composite membrane increased as the AC particle content increased. Authors proposed that the addition of AC particles may affect the pore size, pore distribution, and filtration flux. All this findings are aligned with result observed in this study which shows an increase of water flux with addition of activated carbon and silver nitrate.

Figure 2 clearly shows that the water flux was increasing with increasing activated carbon content. Control membrane alone has the lowest water flux with $5.54 \mathrm{~L} / \mathrm{m} 2 . \mathrm{hr}$ and CM 5 with 0.9 wt. \% of AC content show the highest water flux with $49.33 \mathrm{~L} / \mathrm{m} 2 . \mathrm{hr}$. The incline in flux may be attributed to the increasing of membrane structure porosity.

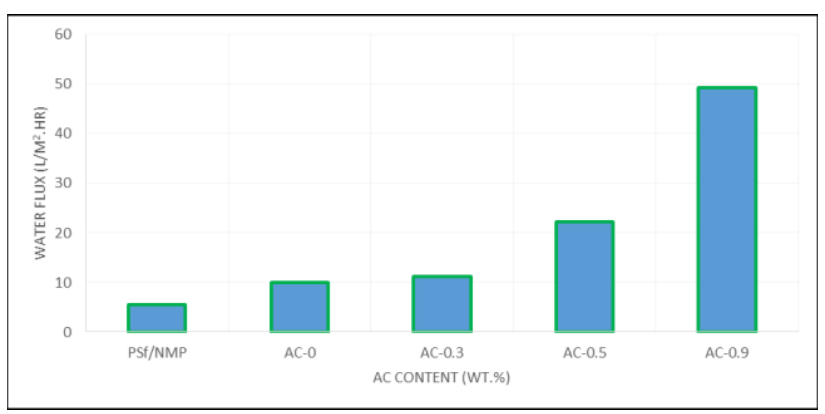

Figure 2. Water flux of different composite membranes

\subsection{Removal of heavy metal}

The adsorption studies were determined by atomic absorption spectrometry (AAS). In this studies, AAS was used to measure the initial and final concentration of heavy metal presence in synthetic wastewater after membrane filtration. To recap, filtration of synthetic wastewater was operated at 3 bar pressure for 30 minutes. Table 3 show the result of heavy metal (chromium, cadmium, lead and silver) rejection for all composite membrane.

Table 3. Rejection percentage of various composite membrane towards chromium, cadmium, lead and silver.

\begin{tabular}{|c|c|c|c|}
\hline Membrane & $\begin{array}{c}\text { Initial } \\
(\mathrm{mg} / \mathrm{L})\end{array}$ & $\begin{array}{c}\text { Final } \\
(\mathrm{mg} / \mathrm{L})\end{array}$ & $\begin{array}{c}\text { Rejection } \\
(\%)\end{array}$ \\
\hline \multicolumn{4}{|c|}{ Chromium } \\
\hline CM 1 & \multirow[t]{5}{*}{159.74} & 3.76 & 97.64 \\
\hline CM 2 & & 137.83 & 13.72 \\
\hline CM 3 & & 135.22 & 15.35 \\
\hline CM 4 & & 131.79 & 17.50 \\
\hline CM 5 & & 128.82 & 19.36 \\
\hline \multicolumn{4}{|c|}{ Cadmium } \\
\hline CM 1 & \multirow[t]{5}{*}{86.78} & 1.23 & 98.5840 \\
\hline $\mathrm{CM} 2$ & & 14.23 & 83.5982 \\
\hline CM 3 & & 55.88 & 35.6111 \\
\hline CM 4 & & 55.49 & 36.0554 \\
\hline CM 5 & & 56.03 & 35.4371 \\
\hline \multicolumn{4}{|c|}{ Lead } \\
\hline CM 1 & \multirow[t]{5}{*}{285.17} & 3.35 & 98.83 \\
\hline CM 2 & & 9.82 & 96.56 \\
\hline CM 3 & & 243.73 & 14.53 \\
\hline CM 4 & & 272.72 & 4.36 \\
\hline CM 5 & & 277.74 & 2.61 \\
\hline \multicolumn{4}{|c|}{ Silver } \\
\hline CM 1 & \multirow[t]{5}{*}{164.47} & 1.75 & 98.93 \\
\hline $\mathrm{CM} 2$ & & 42.29 & 74.14 \\
\hline CM 3 & & 137.77 & 16.24 \\
\hline CM 4 & & 137.66 & 16.30 \\
\hline CM 5 & & 137.43 & 16.44 \\
\hline
\end{tabular}

Rejection of heavy metal are consistent for CM1 between 97 to $98 \%$ most likely caused by small pore size and dense structure shown in figure 1 therefore increase ability of CM1 to entrapped or filtered heavy metal. However the trade-off having high rejection resulting 
CM1 to have a low water flux at $5.54 \mathrm{~L} / \mathrm{m}^{2} . \mathrm{hr}$. In general, the addition of activated carbon has reduce the ability of membrane to filtered heavy metal. CM5 having $0.9 \mathrm{wt} \%$ activated carbon which has the highest water flux of $49.33 \mathrm{~L} / \mathrm{m}^{2} . \mathrm{hr}$ can only manage to remove $19 \%$ of chromium although the rejection value was the highest among membrane with activated carbon but it still lack $78 \%$ from $97 \%$ rejection of control membrane (CM1). Result of cadmium and silver also show CM5 capable of rejecting heavy metal at high water flux but result of lead removal show that at high water flux almost all lead has passed through CM5 as filtrate.

Figure 3 shows the result in graph to observe the trends of heavy metals rejection. In general the trends of rejection show a sudden drop from 75 to $80 \%$ reduction after addition of activated carbon except for chromium rejection.

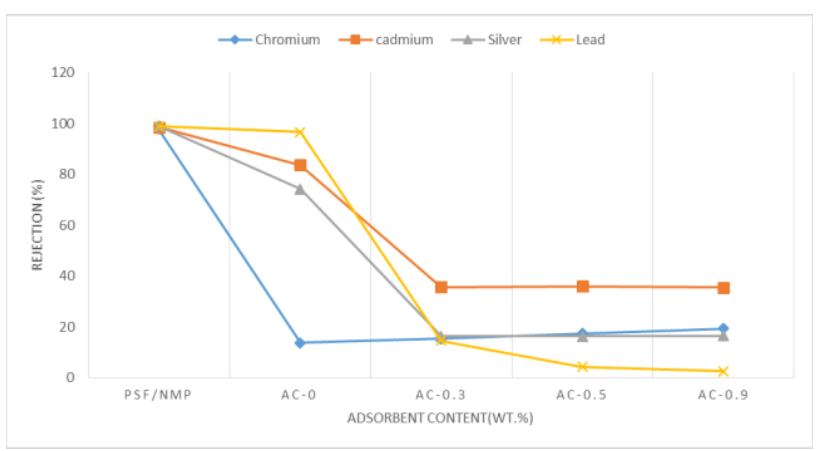

Figure 3. Heavy metal rejection for different membrane composition

Chromium rejection show an increase from approximately $13 \%$ (CM2) to $19 \%$ (CM5) although the gradient was not apparent but the increase of rejection might as well contributed by activated carbon inside the membrane matrix that absorb heavy metal while membrane filtered the remaining. All heavy metal result show approximately $20 \%$ rejection for CM3 while cadmium has more than average rejection at $35 \%$. The result might as well explained by ionic radii of metal ions. The ionic radii follows the following sequence: $\mathrm{Cr}^{3+}$ $(130 \mathrm{pm})>\mathrm{Ag}^{+}(126 \mathrm{pm})>\mathrm{Pb}^{2+}(120 \mathrm{pm})>\mathrm{Cd}^{2+}(97$ pm). The rejection of cadmium was the highest among other metal for CM3 might cause by small ionic radii that give advantage for activated carbon to adsorb by allowing cadmium to enter its pore. Activated carbon has surface area in range of 1000 to $3000 \mathrm{~m}^{2} / \mathrm{g}$ depend on type of activation where the higher surface area refer to small pore size and dense quantity of pore [16-18]. Henceforth, small ionic radii of $97 \mathrm{pm}$ cadmium ion can be adsorb more into pore of activated carbon. After addition of activated carbon, the rejection of cadmium, silver and chromium show a consistent trends within 15 to $19 \%$ for chromium and silver while cadmium show steady rejection at approximately $35 \%$ for CM3 to CM5. Contrasting, the increase of activated carbon composition has reduce the ability of membrane to remove lead where the reduce performance can be observed from figure 3 starting from 14\% (CM3) rejection and eventually drop to $2 \%$ (CM5). Therefore, addition of $0.3 \mathrm{wt} \%$ activated carbon was the optimum composition for heavy metal removal where further increase of composition would either reduce or provide insignificant improvement to heavy metal rejection.

Figure 4 shows the effect of water flux to heavy metal rejection. In general, the increase of flux has significant effect to heavy metal rejection with the lowest flux contribute to highest rejection up to $98 \%$ and sudden reduction was observed for chromium which show steady rejection for the rest of the flux averaging $16 \%$. The high rejection at low flux might contribute to small pore that restrict flow rate which eventually increase rate of separation which are usually based on molecular size. The walls of the pore would change during compaction/operation resulting with denser and closer matrix would be another reason for the increase of rejection while addition of activated carbon has reduce the effect of compaction [19].

In the range of 11 to $49 \mathrm{~L} / \mathrm{m}^{2}$.hr, rejection are constant or steady with value below average from $2 \%$ to $35 \%$ rejection. Consequently, the reduce effect of compaction following addition of activated carbon has allow membrane to swell and increase water flux. Membrane swelling has reduce its ability to filter metal ions while high water flux has reduce the adsorption capacity of activated carbon [20]. It is believed a low water flux would increase the chances of metal ions/heavy metal to adsorb onto the surface of impregnated activated carbon.

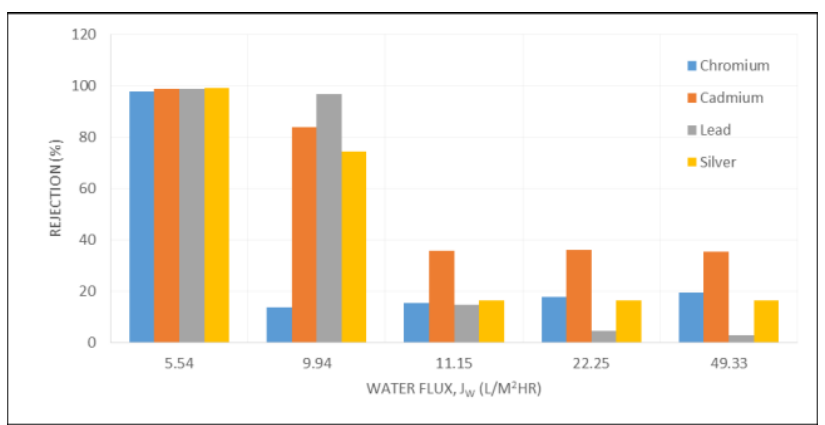

Figure 4. Effect of water flux to heavy metal rejection

Table 4 shows the silver leaching test for CM2 to CM5. The main purpose of conducting silver leaching test was to quantify amount of silver adsorb or filtered by membrane by identifying the rate of silver leach beforehand. Silver leaching refer to detachment of silver from membrane surface or membrane matrix and leach out as filtrate into product stream or to upstream process.

Table 4. Silver leaching test

\begin{tabular}{|c|c|c|c|}
\hline $\begin{array}{c}\text { Membrane } \\
\text { sample }\end{array}$ & \multicolumn{2}{|c|}{$\begin{array}{c}\text { Silver leaching } \\
\text { (mg/L) }\end{array}$} & Total \\
\hline & Day 1 & Day 2 & \\
\hline CM 2 & 6.31 & 0.69 & 7.01 \\
\hline CM 3 & 2.32 & 0.33 & 2.65 \\
\hline CM 4 & 1.93 & 0.69 & 2.62 \\
\hline CM 5 & 1.85 & 0.56 & 2.42 \\
\hline
\end{tabular}

Silver leach reach $7 \mathrm{mg} / \mathrm{L}$ for $\mathrm{CM} 2$ while constant for the rest of composite membrane. CM2 show $5 \mathrm{mg} / \mathrm{L}$ more silver leach, an increase of $71 \%$ which explain the addition of activated carbon has increase the attachment 
of silver onto membrane matrix and eventually reduce the amount of silver leach. Result of heavy metal rejection (Table 3) has taken into consideration of the amount of silver leach from membrane and subtract it from result presented in Table 4.

\section{CONCLUSION}

With the addition of activated carbon, the membrane morphology was modified with increase of water flux. The dense structure of polysulfone membrane (CM1) were changed to a more porous with a lot of macrovoid formation with the addition of activated carbon especially $0.9 \mathrm{wt} \%$ (CM5). The improving porosity of CM3 to CM5 were proved by increasing water flux. Water flux value of CM3, CM4 and CM5 were $55 \%, 77 \%$ and $88 \%$ higher while the cadmium rejection of $\mathrm{CM} 3, \mathrm{CM} 4, \mathrm{CM} 5$ were $63 \%, 62 \%$ and $63 \%$ lower that of CM1, respectively. This is because composite membrane (CM) with added activated carbon experience higher porosity therefore increase the possibility of heavy metal ions to pass through during filtration whereas the high flux has reduce the time for heavy metal to be adsorbed onto activated carbon impregnated in the membrane matrix. Based on the obtained result, it can be concluded that an optimization study to fine-tune the membrane porosity against activated carbon content/composition is desirable to ensure the developed composite membrane (CM) can operate efficiently by mean of filtration application with adsorption capability.

\section{Acknowledgement}

This research is fully supported by FRGS grant, FRGS/TK04(03)/1140/2014(07). The authors fully acknowledged Ministry of Higher Education (MOHE) and Universiti Malaysia Sarawak for the approved fund which makes this important research viable and effective.

\section{References}

1. H. Strathmann, L. Giorno, E. Drioli, An Introduction to Membrane Science and Technology, 2006.

2. C.M. Lewandowski, A Brief Mindfulness Intervention on Acute Pain Experience: An Examination of Individual Difference., 2015.

3. Y. Yurekli, Removal of heavy metals in wastewater by using zeolite nano-particles impregnated polysulfone membranes, J. Hazard. Mater. 309 (2016) 53-64. doi:10.1016/j.jhazmat.2016.01.064.

4. F. Fu, Q. Wang, Removal of heavy metal ions from wastewaters: A review, J. Environ. Manage. 92 (2011) 407-418. doi:10.1016/j.jenvman.2010.11.011.

5. E. Bernard, a Jimoh, J.O. Odigure, Heavy Metals Removal from Industrial Wastewater by Activated Carbon Prepared from Coconut Shell, Res. J. Chem. Sci. 3 (2013) 3-9.

6. M.J.K. Ahmed, M. Ahmaruzzaman, A review on potential usage of industrial waste materials for binding heavy metal ions from aqueous solutions, J. Water Process Eng. 10 (2016) 39-47. doi:10.1016/j.jwpe.2016.01.014.

7. S. Fazal, B. Zhang, Z. Zhong, L. Gao, X. Chen, Industrial Wastewater Treatment by Using MBR ( Membrane Bioreactor ) Review Study, J. Environ. Prot. (Irvine,. Calif). 6 (2015) 584-598.

8. H.A. Hegazi, Removal of heavy metals from wastewater using agricultural and industrial wastes as adsorbents, HBRC J. 9 (2013) 276-282. doi:10.1016/j.hbrcj.2013.08.004.

9. M. Karnib, A. Kabbani, H. Holail, Z. Olama, Heavy metals removal using activated carbon, silica and silica activated carbon composite, in: Energy Procedia, 2014: pp. 113-120. doi:10.1016/j.egypro.2014.06.014.

10. D. Lakherwal, Adsorption of Heavy Metals: A Review, Int. J. Environ. Res. Dev. 4 (2014) 22493131. doi:10.1007/s11270-007-9401-5.

11. A.F. Ismail, A.R. Hassan, Effect of additive contents on the performances and structural properties of asymmetric polyethersulfone ( PES ) nanofiltration membranes, $55 \quad$ (2007) 98-109. doi:10.1016/j.seppur.2006.11.002.

12. L.L. Hwang, J.C. Chen, M.Y. Wey, The properties and filtration efficiency of activated carbon polymer composite membranes for the removal of humic acid, Desalination. $\quad 313 \quad$ (2013) 166-175. doi:10.1016/j.desal.2012.12.019.

13. X. Lin, K. Wang, Y. Feng, J.Z. Liu, X. Fang, T. Xu, H. Wang, Composite ultrafiltration membranes from polymer and its quaternary phosphoniumfunctionalized derivative with enhanced water flux, J. Memb. Sci. $482 \quad$ (2015) 67-75. doi:10.1016/j.memsci.2015.02.017.

14. P.F. Andrade, A.F. de Faria, S.R. Oliveira, M.A.Z. Arruda, M. do C. Gonçalves, Improved antibacterial activity of nanofiltration polysulfone membranes modified with silver nanoparticles, Water Res. 81 (2015) 333-342. doi:10.1016/j.watres.2015.05.006.

15. H.L. Richards, P.G.L. Baker, E. Iwuoha, Metal Nanoparticle Modified Polysulfone Membranes for Use in Wastewater Treatment: A Critical Review, J. Surf. Eng. Mater. Adv. Technol. 02 (2012) 183-193. doi:10.4236/jsemat.2012.223029.

16. L. Li, S. Liu, J. Liu, Surface modification of coconut shell based activated carbon for the improvement of hydrophobic VOC removal, J. Hazard. Mater. 192 (2011) 683-690. doi:10.1016/j.jhazmat.2011.05.069.

17. X. Yao, J. Liu, G. Gong, Y. Jiang, Q. Xie, Preparation and modification of activated carbon for benzene adsorption by steam activation in the presence of KOH, Int. J. Min. Sci. Technol. 23 (2013) 395-401. doi:10.1016/j.ijmst.2013.05.015.

18. J. Alcañiz-Monge, M.J. Illán-Gómez, Insight into hydroxides-activated coals: Chemical or physical activation?, J. Colloid Interface Sci. 318 (2008) 3541. doi:10.1016/j.jcis.2007.10.017.

19. E. Eren, A. Sarihan, B. Eren, H. Gumus, F.O. Kocak, Preparation, characterization and performance enhancement of polysulfone ultrafiltration membrane using PBI as hydrophilic modifier, J. Memb. Sci. 475 (2015) 1-8. doi:10.1016/j.memsci.2014.10.010.

20. P.S.S. Goh, A.F.F. Ismail, S.M.M. Sanip, B.C.C. Ng, 
M. Aziz, Recent advances of inorganic fillers in mixed matrix membrane for gas separation, Sep.

Purif. Technol. $81 \quad$ (2011) 243-264.

doi:10.1016/j.seppur.2011.07.042. 